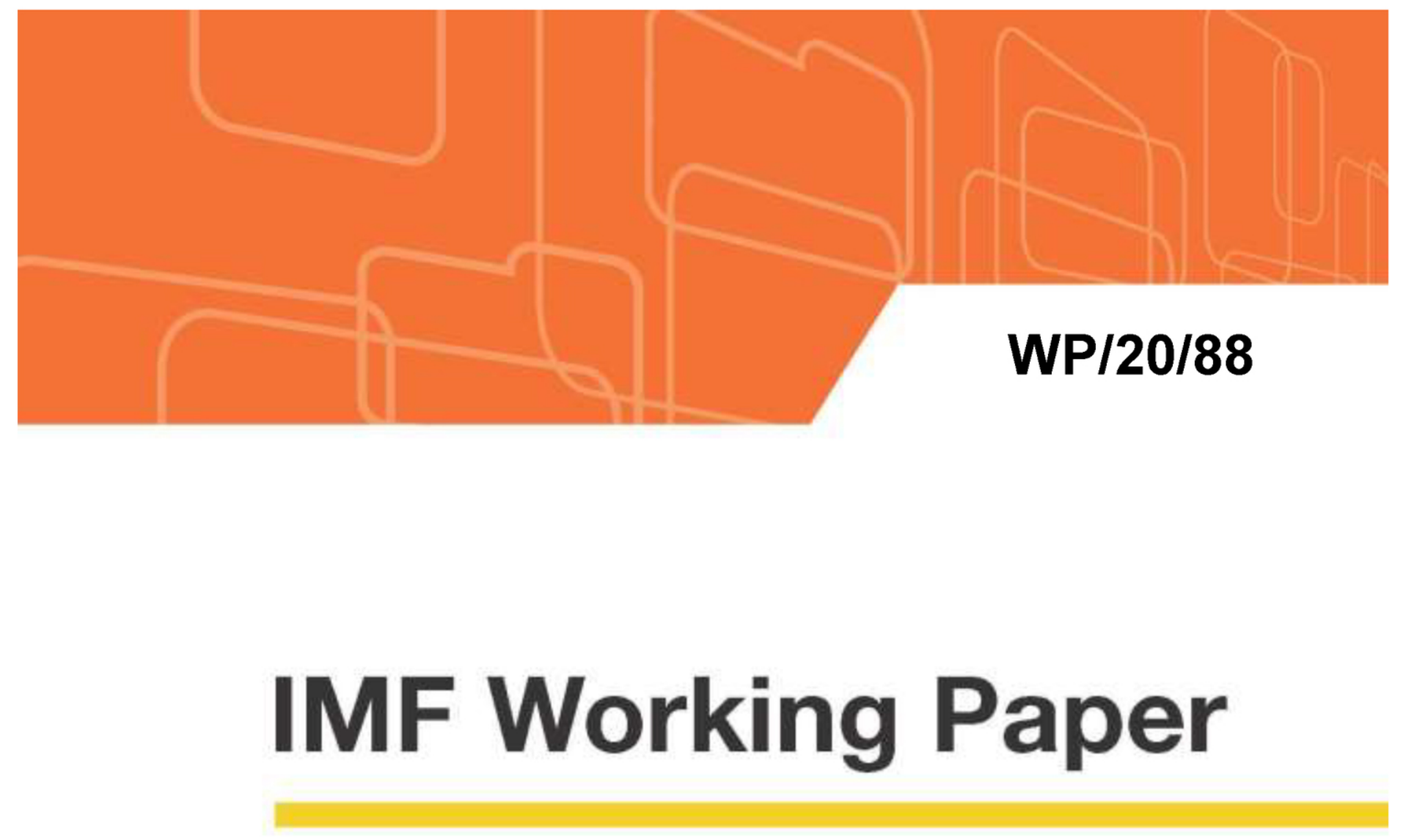

\title{
Who will Bear the Brunt of Lockdown Policies? Evidence from Tele-workability Measures Across Countries
}

by Mariya Brussevich, Era Dabla-Norris and Salma Khalid

IMF Working Papers describe research in progress by the author(s) and are published to elicit comments and to encourage debate. The views expressed in IMF Working Papers are those of the author(s) and do not necessarily represent the views of the IMF, its Executive Board, or IMF management. 


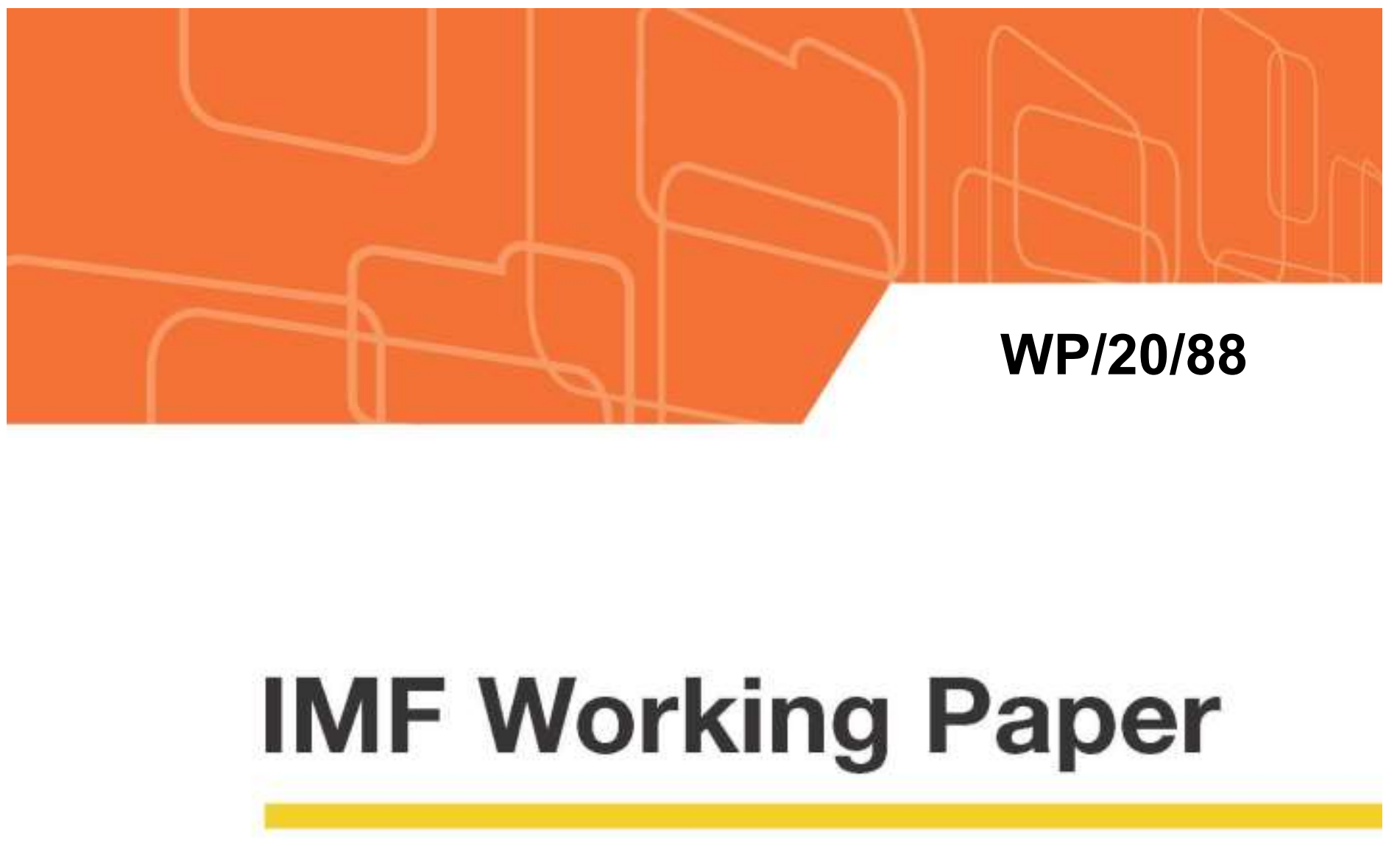

\section{Who will Bear the Brunt of Lockdown Policies? Evidence from Tele-workability Measures Across Countries}

by Mariya Brussevich, Era Dabla-Norris and Salma Khalid

IMF Working Papers describe research in progress by the author(s) and are published to elicit comments and to encourage debate. The views expressed in IMF Working Papers are those of the author(s) and do not necessarily represent the views of the IMF, its Executive Board, or IMF management. 


\title{
IMF Working Paper
}

Asia and Pacific Department

\section{Who will Bear the Brunt of Lockdown Policies? Evidence from Tele-workability Measures Across Countries}

\author{
Prepared by Mariya Brussevich, Era Dabla-Norris, and Salma Khalid"
}

Authorized for distribution by Era Dabla-Norris

June 2020

IMF Working Papers describe research in progress by the author(s) and are published to elicit comments and to encourage debate. The views expressed in IMF Working Papers are those of the author(s) and do not necessarily represent the views of the IMF, its Executive Board, or IMF management.

\begin{abstract}
Lockdowns imposed around the world to contain the spread of the COVID-19 pandemic are having a differential impact on economic activity and jobs. This paper presents a new index of the feasibility to work from home to investigate what types of jobs are most at risk. We estimate that over 97.3 million workers, equivalent to about 15 percent of the workforce, are at high risk of layoffs and furlough across the 35 advanced and emerging countries in our sample. Workers least likely to work remotely tend to be young, without a college education, working for non-standard contracts, employed in smaller firms, and those at the bottom of the earnings distribution, suggesting that the pandemic could exacerbate inequality. Crosscountry heterogeneity in the ability to work remotely reflects differential access to and use of technology, sectoral mix, and labor market selection. Policies should account for demographic and distributional considerations both during the crisis and in its aftermath.
\end{abstract}

JEL Classification Numbers: D24, J22, J61, O30, R12, R32

Keywords: COVID-19, labor markets, inequality,working remotely

Author’s E-Mail Address: mbrussevich@imf.org; edablanorris@imf.org; skhalid@imf.org

\footnotetext{
* We would like to thank Kalpana Kochhar, Kenneth Kang, and APD, RES, FAD, and AFR reviewers for their comments. Hibah Khan and Ross Rattanasena provided excellent research and editorial assistance.
} 
Table of Contents

I. Introduction 4

II. Data and Methodology $\underline{6}$

III. Main Findings

A. Tele-workability Index and Occupations

B. Who Holds These Jobs? $\underline{10}$

IV. Conclusion $\underline{17}$

FIGURES

1. Tele-workability by Occupation $\underline{8}$

2. Tele-workability Index by GDP per capita (PPP)__

3. Tele-workability by Sector 10

4. Tele-workability Index by Worker Characteristics 11

5. Tele-workability Index by Age Group and Education Level $\underline{13}$

6. Tele-workability Index by Hourly Earnings Decile 14

7a. Distribution of Occupations across Earnings Quintiles $\underline{15}$

7b. Distribution of Sectors across Earnings Quintiles $\underline{15}$

8: Differences in Tele-workability between Top and Bottom Earnings Deciles across Countries

Annex 1. Occupational Classifications $\underline{19}$

Annex 2. Country Estimates of Tele-workability Differences by Worker

Characteristics $\underline{20}$

Annex 3. Gender Differences Across Sectors and Occupations 21

Annex 4. Employment at Risk Estimates $\underline{22}$

References $\underline{23}$ 


\section{Introduction}

Social distancing policies implemented to contain the COVID-19 pandemic are affecting a large share of workers across the world. Millions of workers are unemployed and countless jobs are increasingly at risk. ${ }^{1}$ Workers in occupations requiring physical presence at the workplace or those jobs that require a high level of personal proximity have limited scope for working from home. Some of these workers commensurately face higher risk of reductions in hours or pay, temporary furloughs, or permanent layoffs. What type of jobs are most at risk? How does the level of "tele-workability" depend on worker characteristics, such as age, educational attainment, gender, employment status, and earnings? How does the feasibility to work remotely vary across advanced and emerging economies? Answers to these questions can inform the social protection and labor market policies needed to support workers both during and after lockdowns.

We construct new index of "tele-workability" for 35 advanced and emerging market economies using a task-based approach. We use two sources of data to develop a measure of teleworkability: occupation-level classification of feasibility of working from home derived by Dingel and Neiman (2020) for the US and individual-level data from the OECD's Programme for the International Assessment of Adult Competencies (PIAAC). The latter has the advantage of measuring task or skill content at the worker level for a large sample of countries. Our estimation approach relies on an Expectation Maximization algorithm to map occupation-level measures of the feasibility of working at home to individual-level observations in the PIAAC dataset and derive predicted tele-workability scores for each worker. Individual-level scores allow us to conduct a more nuanced analysis of worker characteristics at the task-level for a large group of countries. Given that PIAAC surveys are representative at the national level, we are able to capture differences in the ability to telework that are driven by underlying differences in the sectoral mix, demographic composition, and access to technologies necessary for teleworking across countries.

We find that workers least likely to work remotely are concentrated in the sectors hit hardest by the crisis (ILO, 2020): accommodation and food services, transportation, and retail and wholesale sectors. We estimate that over 97.3 million workers, equivalent to about 15 percent of the workforce, are at high risk of layoffs and furlough across the countries in our sample. Vulnerable workers tend to be young, without a college education, in less secure work arrangements (e.g., on temporary contracts or self-employed), and employed in small and medium enterprises (SMEs). Workers at the bottom of the earnings distribution are most at risk of earnings loss, suggesting that the COVID-19 crisis could exacerbate inequality. Cross-country heterogeneity reflects differences in the structure of production (e.g., size of manufacturing versus services sectors), use of technology, and labor market selection, and thus differential distribution of workers across jobs. Workers in emerging market economies are likely to face significant challenges during strict lockdowns given limited access to technology. Interestingly, differences

${ }^{1}$ ILO (2020), BLS (2020). 
in earnings and ability to work remotely are less stark for those at the top and bottom of the earning distribution in emerging market economies compared to some advanced economies.

This paper contributes to the literature examining workers' ability to perform their jobs from home and the labor market consequences. Evidence from the US (Dingel and Neiman, 2020; Mongey, Pilossoph, and Weinberg, 2020; Hensvik, Le Barbanchon, and Rathelot, 2020) and several advanced European countries (Boeri, Caiumi, Paccagnella, 2020; Fadinger and Schymik, 2020; Office of National Statistics, 2020) suggests that about 40 percent of jobs can be performed at home, ranging from 24 percent in Italy to 42 percent in Germany. ${ }^{2}$ In developing economies, up to 20 percent of urban population can work from home (Saltiel, 2020; Gottlieb, Grobovsek, and Poschke, 2020); the number is much smaller if the rural population is taken into account. All of these studies use occupational-level data to examine labor market implications of social distancing policies.

In this paper, we go beyond occupational classifications of feasibility of teleworking and zoom in on the socio-economic characteristics of workers along the entire distribution of tele-workability using comparable data for a large set of advanced and emerging economies. By doing so, we account for the heterogeneity of workers' tasks within a given occupation. Specifically, since our estimation approach specifies which tasks or activities occur within a given job, this provides a more granular understanding of how social distancing policies can affect individual workers. Second, our task-based approach also allows us to relax the assumption implicit in other studies that workers have access to the same technologies across countries to perform their tasks.

Finally, our methodology also provides a more realistic picture of the jobs at-risk within a given occupation compared to other cross-country studies. A common approach in the literature that examines cross-country differences in the feasibility to work from home is to apply the index developed by Dingel and Neiman (2020) at the 5-digit SOC level for the US to 1- or 2-digit ISCO occupational level for other countries. This methodology assumes that all narrowly defined occupations within the single-digit occupations have the same level of tele-workability and can substantially over- or under-state the level of tele-workability for a given individual. Our approach accounts for individual-level heterogeneity and thus sidesteps the assumption of equal tele-workability scores within each broadly defined occupation. For instance, compared to Gottlieb, Grobovsek, and Poschke (2020) who find that over 70 percent of managers and professionals can work from home, we show that these occupations have a significantly lower level of tele-workability at about 42 percent.

This paper is structured as follows. The next section presents the data and methodology. Section III presents the main findings, and Section IV concludes.

\footnotetext{
${ }^{2}$ Mongey, Pilossoph, and Weinberg (2020), Boeri, Caiumi, and Paccagnella (2020) and Fadinger and Schymik (2020) rely on occupation-level classifications of the feasibility of working from home similarly to Dingel and Neiman (2020) to derive country-level estimates. An alternative methodology adopted by Hensvik, Le Barbanchon, and Rathelot (2020) and the Office of National Statistics (2020) relies on time-use and population surveys to estimate the share of workers able to work from home and produces similar results.
} 


\section{Data and Methodology}

We combine two sources of data to develop our measures for tele-workability: occupation-level classification of the feasibility of working from home derived by Dingel and Neiman (2020) for the US and worker-level data for 35 countries from the OECD's Programme for the International Assessment of Adult Competencies (PIAAC).

Dingel and Neiman (2020) use Occupational Information Network (O*NET) survey data from the US to designate whether an occupation can feasibly be performed from home, based on information about "work context" and "generalized work activities." The survey questions used for this classification capture information such as whether work is done outside, whether it requires specialized equipment, requires physical activity, etc. Their index of tele-workability takes on values of 0 or 1 and is assigned at the level of 6 -digit SOC codes.

To extend this concept to a cross-country level, we use recent rounds of the OECD's Programme for the International Assessment of Adult Competencies (PIAAC) database which collects nationally representative individual-level information for 35 advanced and emerging countries. This survey contains demographic data for workers in addition to information on their occupations and sectors of employment. In addition, the survey captures detailed information on the nature of work activities, such as physical work associated with caregiving and operating construction-related equipment, flexibility in performing tasks, flexibility in work hours, whether interpersonal tasks are performed (e.g., writing reports, solving complex problems, and negotiating with people), use of technology or software in the workplace, among others. Most country questionnaire items contain five responses indicating the frequency at which a task is performed: never, less than once a month, less than once a week but at least once a month, at least once a week but not every day, and every day.

In order to combine the two data sources, we map occupational categories from the $\mathrm{O} N \mathrm{NET}$ data to the PIAAC data. PIAAC data contains occupational information at the 2-digit ISCO classification level, which is a higher level of aggregation than the 6-digit SOC codes in O*NET, resulting in one PIAAC occupation being potentially mapped to several measures of teleworkability (see Annex 1). This allows us to relate tele-workability of occupations to job content and worker characteristics. Our methodology also provides crucial insights into which occupations and jobs may be at risk of continued disruption in the post-COVID era due to potential changes in consumer preferences, containment measures and even repeat lockdown

We allow individual workers to be mapped to multiple indices of tele-workability, based on the crosswalk between the 6 -digit SOC codes and the 2-digit ISCO codes. We then use the iterative Expected Maximization (EM) algorithm where individual-level data (demographic data and work characteristics) is regressed on associated measures of the tele-workability index, in order to find the model of best fit between worker characteristics and occupation level tele-workability using data for US workers only (see Arntz, Gregory, and Zierahn , 2017; Brussevich, Dabla-Norris and Khalid, 2019, for details on this methodology). Specifically, we estimate an individual-level regression: 


$$
t_{i j}=\sum_{n=1}^{N} \beta_{n} X_{i n}+\epsilon_{i j}
$$

where $i$ denotes individuals, $j$ denotes duplicates of these individuals when multiple probabilities are associated with one individual due to differences in the aggregation level of occupations, $t_{i j}$ is the tele-workability score, and $X_{\text {in }}$ contains $N$ individual, job, and task characteristics. $\beta_{n}$ are parameters which capture the impact of the regressors on the probability of tele-workability, which lies between 0 and 1. To run the EM algorithm, we use a set of individual characteristics (gender, education, income deciles, immigration status, age), a set of skills used in the workplace (use of computer, Internet, email, spreadsheets, communication software, presentation skills, and a set of work characteristics such as physical/manual work, autonomy to change one's schedule or how one's job is performed and set the schedules of others, as well as training others. Using individual-level data, allows us to account for the fact that individuals within the same occupation often perform different tasks.

We use a weighted Generalized Linear Model (GLM) for our estimation, with equal initial weights for all duplicates $j$ for individual $i$. For each iteration of the regression, we compare the prediction from our estimated model with the Dingel and Neiman (2020) occupation-level measure and recalculate the weights as per Ibrahim (1990):

$$
w_{i j}=\frac{f\left(\hat{t}-t_{i j} \mid x_{i n}, \beta_{n}\right)}{\sum_{n=1}^{N} f\left(\hat{t}-t_{i j} \mid x_{i n}, \beta_{n}\right)}
$$

where $f($.$) is the standard normal density and \hat{t}$ is the predicted value. Once weights converge and best fit is achieved, the estimated parameters $\beta_{n}$ are applied to worker characteristics for all countries in the PIAAC sample, allowing us to estimate the probability of tele-workability across the full sample at the level of individual workers. The tele-workability index takes on values between 0 and 1, with higher numbers indicating greater feasibility of working from home.

\section{Main Findings}

\section{A. Tele-workability Index and Occupations.}

Averages of our individual-level tele-workability index across broadly defined occupations in Figure 1 are consistent with the patterns documented by the original occupational-level index developed by Dingel and Neiman (2020) and a follow-up study on worker characteristics by Mongey, Pilossoph, and Weinberg (2020) for the United States. Elementary occupations (e.g., janitors, construction laborers, street vendors) are least able to work from home, followed by plant and machinery operators and craft and related trades workers (e.g., mechanics, garments

workers). At the other end of the spectrum, professionals, managers, officials and legislators are the occupations most amenable to working from home.

There is significant cross-country variation in the scope to work remotely, with Turkey exhibiting lower tele-workability scores across all occupations, suggesting that fewer jobs can be performed at home. However, rankings across occupations are broadly preserved within our sample of countries. Figure 2 shows the association between the level of economic development and the 
ability to work remotely. Turkey, Chile, Mexico, Ecuador, and Peru stand out with significantly lower average tele-workability scores. ${ }^{3}$ This suggests that workers in emerging and developing economies could face daunting challenges in continuing to work during periods of stringent lockdowns. Within advanced economies, Greece, and Italy have among the lowest teleworkability scores, while Nordic countries and Singapore have the highest scores, reflecting their relatively developed digital economies.

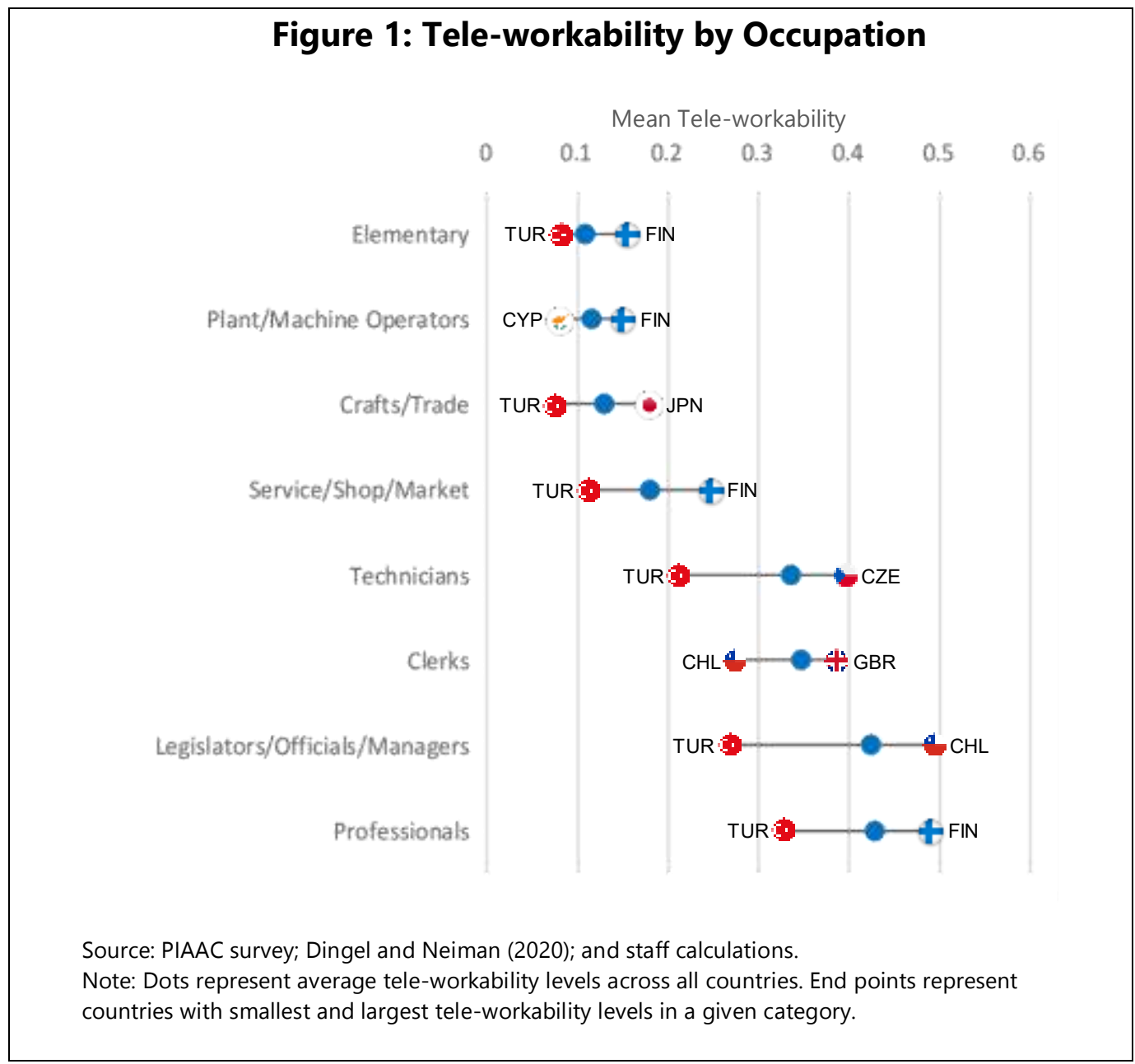

\footnotetext{
${ }^{3}$ For a subset of PIAAC countries, we perform a robustness check by recreating the country level tele-workability index using sector-level tele-workability weighted by value added and labor share of each sector (from EU KLEMS data) in the respective countries. Our alternative estimates for country-level tele-workability averages very closely mirror the estimates from the PIAAC sample.
} 


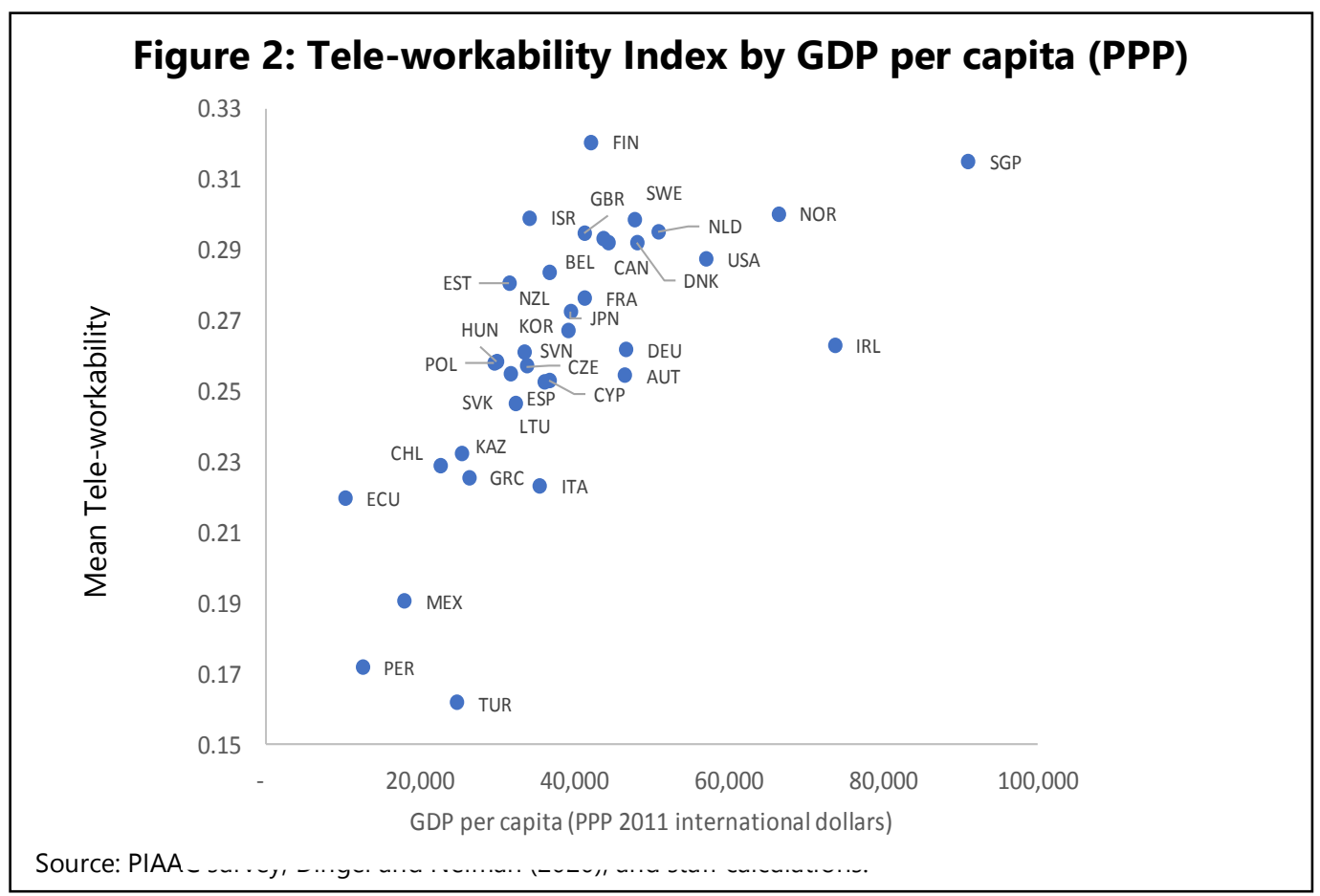

Figure 3 shows the distribution of the computed index score across different sectors. On average, workers with a lower scope for working from home are concentrated in accommodation and food services, transportation, wholesale and retail trade, health and social services, and manufacturing sectors (Figure 3). Within these sectors, essential activities in critical supply chains (food, pharmaceuticals, deliveries, healthcare, as well as some types of manufacturing) have been exempt from lockdown restrictions in most countries. By contrast, sectors best suited for teleworking include information and communication, finance and insurance and professional services (e.g., legal services and scientific research), as they typically require less physical proximity and have higher reliance on digital tools and technologies. As in the case of occupations, there is a negative association between level of economic development and the feasibility to work remotely within a given sector. Workers in Finland, Singapore, and Lithuania have higher index scores even in less telework-able sectors such as manufacturing and retail, given greater use of digital technologies in these countries. 


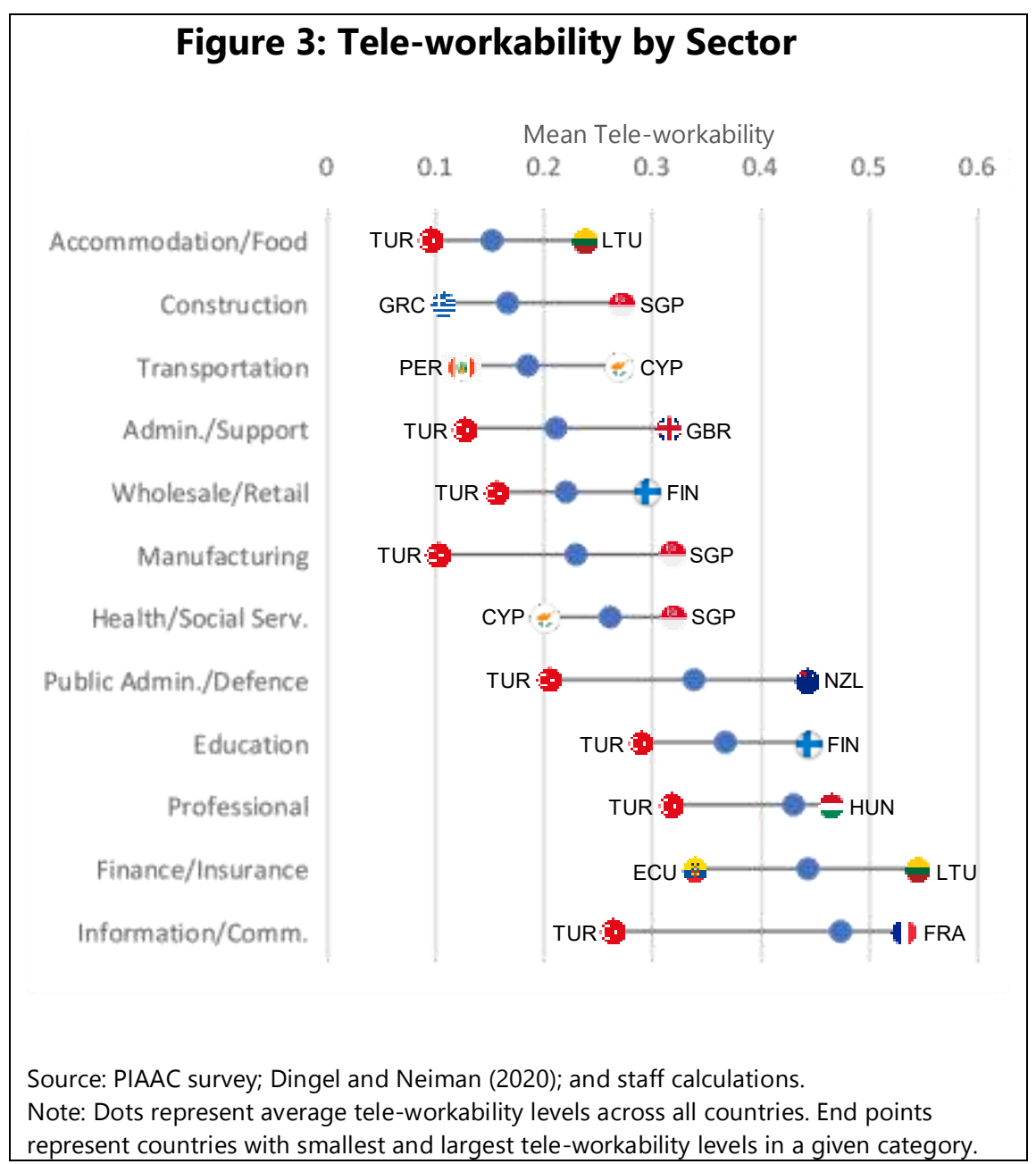

\section{B. Who Holds These Jobs?}

We next turn to an examination of the labor market implications of social distancing policies for specific categories of workers and the resulting implications for inequality. To correlate demographic characteristics with our estimate of tele-workability, we run a simple regression of the form:

Teleworkability $_{\mathrm{ic}}=\alpha_{\mathrm{ic}}+\beta * \mathrm{X}_{\mathrm{ic}}+\gamma_{\mathrm{c}}+\varepsilon_{\mathrm{ic}}$,

where Teleworkability $\mathrm{ic}_{\mathrm{ic}}$ is an index ranging from 0 to 1 for an individual $i$ in country $c$ and $\mathrm{X}_{\mathrm{ic}}$ a demographic variable of interest (gender, age, hourly earnings, whether born abroad, job stability, and firm size), and $\gamma_{c}$ are country fixed effects. All demographic characteristics are expressed as binary variables and a positive coefficient $\beta$ indicates higher feasibility of working from home for a given group relative to its counterpart. We plot the point estimates for each of these characteristics in Figure 4, ordering these attributes from the highest to the lowest point estimate, with ranges for different countries. Annex 2 presents country-level model estimates and $p$ values, estimated using interactions of each demographic variable with a country indicator variable, to capture differences of each country from the full sample mean. Overall, our results 
suggest that risks of income and employment loss fall disproportionately on vulnerable groups of workers.

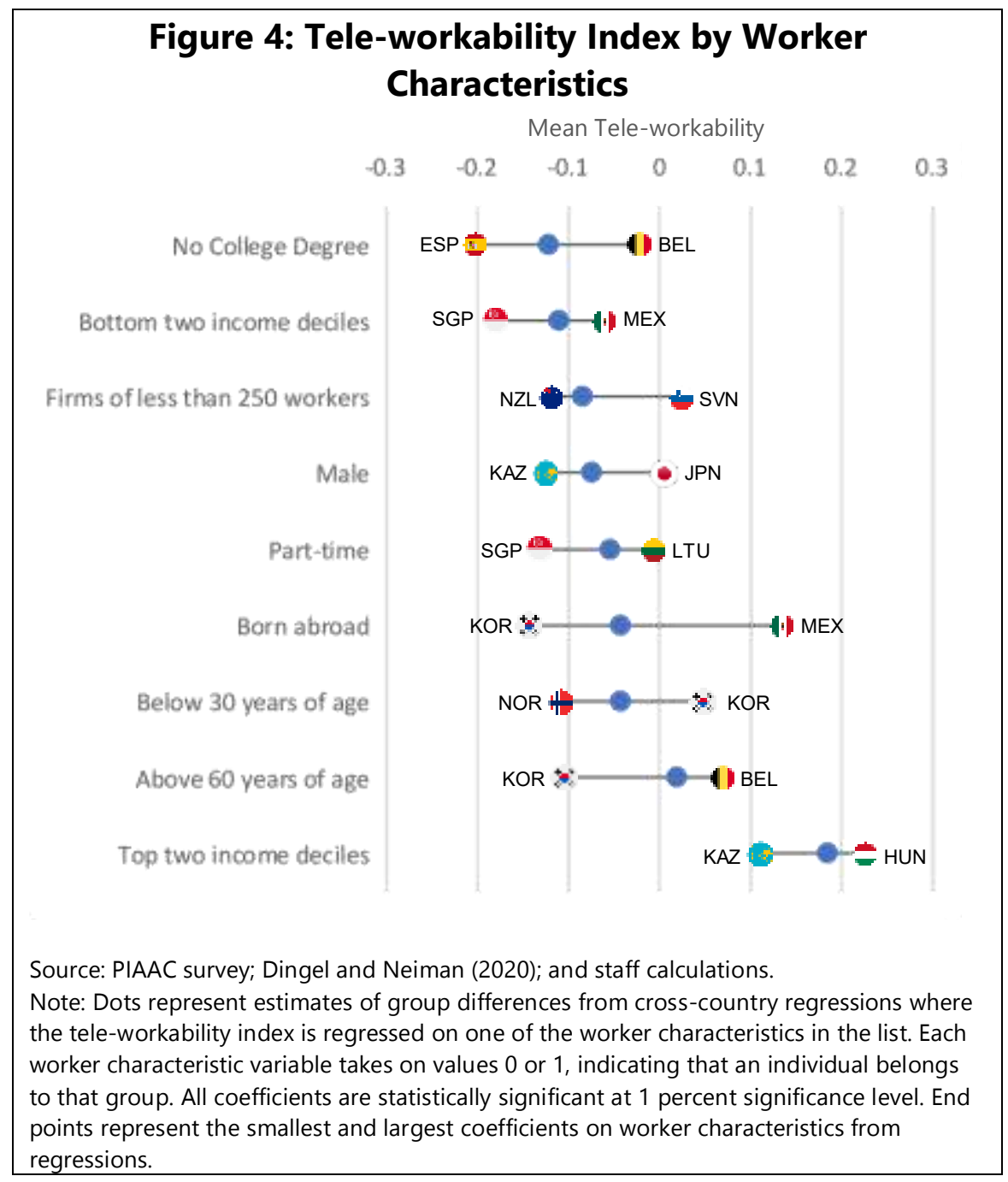

\section{Gender}

We find that men, on average, are less likely to be engaged in work activities that can be performed at home compared to women. Japan is an exception as the difference between men's and women' ability to work remotely is not statistically different from zero. This outcome is related to selection of men and women into occupations and sectors (see Annex 3). Men, for instance, are more likely to work as plant and machine operators and crafts and trade workers, and in construction, transportation, and manufacturing sectors. Women's employment is often concentrated in the public sector and in the care and education sectors. This suggests that female workers could be less affected by the physical lockdowns and social distancing measures currently in place in many advanced and emerging countries. ${ }^{4}$ At the same time, female workers

\footnotetext{
${ }^{4}$ These results depend on the extent to which women have access to digital tools. Women's jobs tend to be at higher risk in countries with a larger digital gender divide (see Brussevich, Dabla-Norris, and Khalid, 2019).
} 
who lack access to adequate leave in case of sickness or disproportionately shoulder care responsibilities may have to cut down their activities or even leave their jobs entirely. ${ }^{5}$ Women could also be at greater risk of job loss if demand for accommodation and food services, tourism, and retail services, which account for a sizeable share of their labor force participation, particularly for low-skill workers, does not recover when social distancing measures are unwound. This is already borne out by data from the US, which shows that women's labor market prospects were disproportionately affected by the crisis (BLS, 2020). ${ }^{6}$

\section{Age and Educational Attainment.}

Older workers (aged 60 and above), on average, are slightly more likely to hold jobs with a high tele-workability score as compared to younger workers (under 30). This result, however, varies significantly across countries, with more than a third of coefficients being negative and statistically significant. In Asian countries (Korea, Singapore, Japan) and some emerging market economies (e.g., Kazakhstan, Ecuador) older workers are less likely to be engaged in jobs amenable to teleworking. This reflects broad differences in adoption of automation technologies and educational attainment of workers across countries.

Workers without a college degree are significantly less likely to work in jobs that can be performed at home relative to their more educated peers. This result holds across most countries. For a given occupation, workers with low levels of educational attainment in Spain, Italy, Ecuador and Mexico have the lowest tele-workability scores. Comparing age profiles against sectors, this higher risk for young employees is consistent with the relatively younger age profiles of the most affected sectors, such as wholesale and retail and accommodation and food services.

We next evaluate differences in ability to work remotely by age and education together. On average, having a college degree greatly improves the likelihood of working remotely across all age groups (Figure 5). However, older workers with lower levels of education still have higher levels of tele-workability, reflecting lifecycle effects as there is a natural progression into more senior-level occupations over a worker's career. These findings also suggest that earnings and income gaps between generations that were exacerbated by the Global Financial Crisis (DablaNorris, Pizinelli, and Rappaport 2019), could widen even further after the current crisis, with less educated, younger workers the hardest hit in many countries. ${ }^{7}$

\footnotetext{
${ }^{5}$ Gender gaps in unpaid work are largest in Japan and Korea (2.5 hours) and Turkey (4 hours per day), where traditional norms on gender roles prevail (Alonso et. al., 2019).

${ }^{6}$ Data from the US shows that the unemployment rate for women ages 16 and over rose from 3.4 percent in February 2020 to 16.2 percent in April 2020. This is 2.7 percentage points higher than the unemployment rate for men the same age (13.5 percent). The unemployment rates for women are now higher and have risen faster than the same rates for men across all age groups (BLS, 2020).

${ }^{7}$ In many European countries, for instance, incomes declined sharply for young people after the 2007 crisis due to unemployment, and only recovered very slowly, pointing to long-lasting scarring in labor markets (Chen et al. 2018).
} 


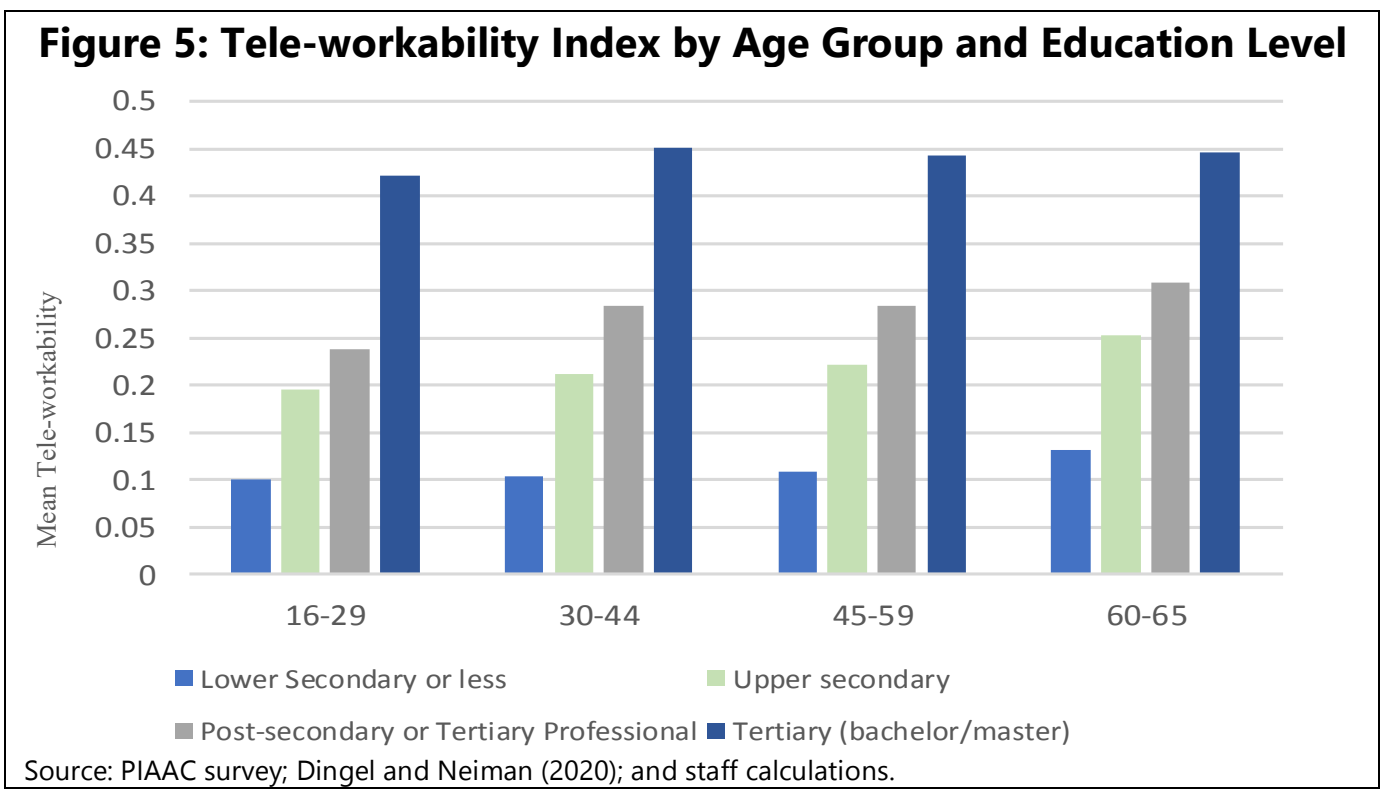

\section{Job Characteristics}

Workers employed in part-time or temporary jobs are less likely to work remotely. Part-time workers in Singapore and Korea, in particular, have significantly lower tele-workability scores compared to those in more permanent jobs. Within Europe, temporary contracts account for a sizeable fraction of total employment in Spain, Poland and the Netherlands (OECD, 2019). This is particularly the case for sectors most affected by lockdowns. Part-time and temporary workers could thus be at greater risk of job loss as it is less costly for firms to shed workers hired under non-standard contracts. At the same time, they typically have limited protection against the risk of job or income loss because of lower contributions or lack of entitlement to paid sick leave, unemployment benefits and other income support.

Workers in SMEs (with less than 250 workers), which account for the majority of jobs in most economies, are less likely to be in jobs that are amenable to teleworking compared to workers in larger enterprises. This may be a result of SMEs lagging behind larger firms in their adoption of digital technologies even in advanced economies. Differences in tele-workability scores for workers in SMEs as compared to larger firms, however, are less stark in many Eastern European countries. Overall, the risk of employment loss is higher in SMEs, as smaller firms also tend to be more liquidity constrained, have less of a capital cushion to continue paying furloughed employees, and may be less likely to survive the lockdown period. This is corroborated by recent firm surveys in OECD countries which find that half the SMEs already face severe cashflow problems, with many only having a few months reserves to withstand the crisis (OECD, 2020).

\section{Immigration Status}

Foreign-born individuals, on average, are significantly more likely to belong to occupations which are less amenable to teleworking. They also often lack access to emergency assistance and social insurance. This difference is more marked in European countries than in the United States. In 
Peru and Mexico, however, foreign-born workers have higher tele-workability score, on average, potentially reflecting selection of higher-skilled immigrants in emerging market countries.

\section{Earnings Distribution}

The likelihood of working in an occupation that is amenable to teleworking is also very strongly correlated with worker hourly earnings, with workers in the bottom two deciles of the hourly earnings distribution significantly less likely to work remotely than workers in the top two deciles (Figure 6). Not surprisingly, workers in the bottom earnings quintiles are concentrated in occupations and sectors where work cannot be plausibly done from home (Figures 7a-b). Across countries, workers in the bottom deciles are also more likely to live hand-to-mouth and to have lower financial buffers. This suggests that such workers will find that staying at home is an unaffordable option and could be at high risk of employment and income loss in the future.

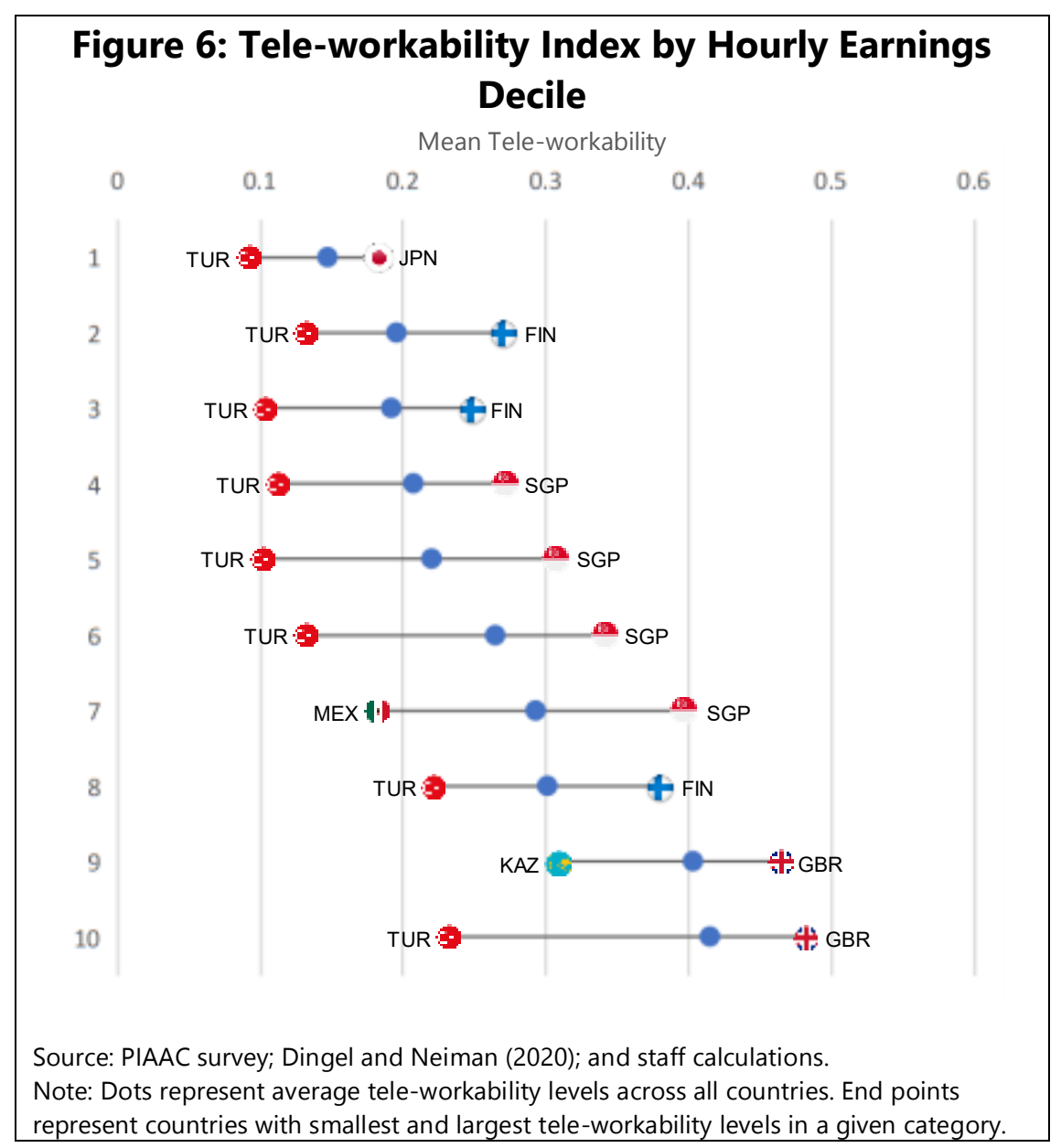

CInternational Monetary Fund. Not for Redistribution 

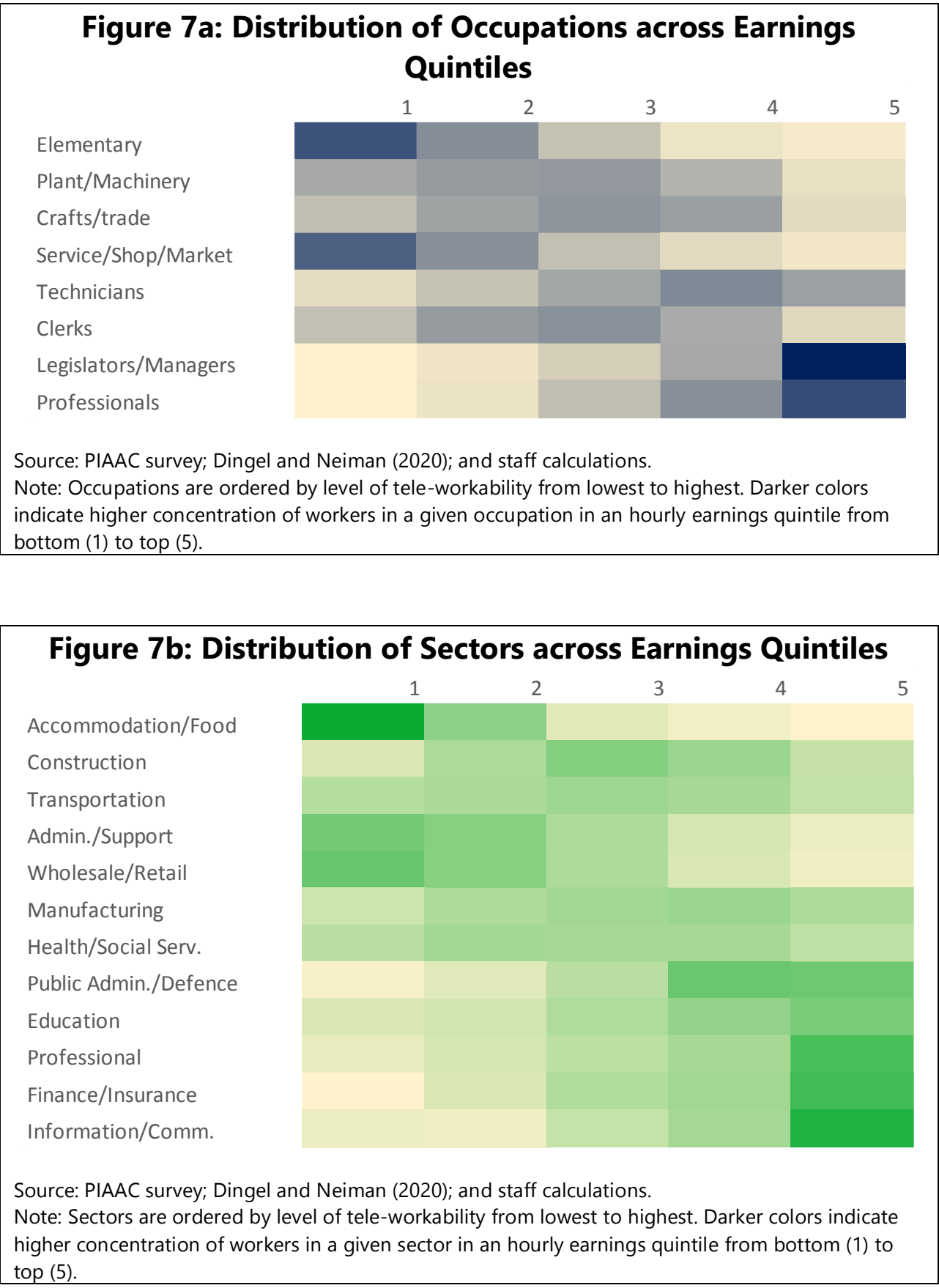

Individual-level estimates of the tele-workability index also allow us to evaluate the distributional implications of the lockdown policies across countries. For each country in the sample, we compute the ratio of average tele-workability levels between top and bottom earnings deciles (Figure 8). While the average tele-workability score is significantly lower in Turkey than in Singapore (Figure 2), earnings disparity between top and bottom deciles is significantly higher in the latter. Similarly, disparities in the ability to work from home are much wider for workers in top and bottom earnings deciles in Hungary, Slovenia, Netherlands, and the US. These results demonstrate how in the absence of supportive policies both during the lockdown period and in 
its aftermath, the economic fallout of the pandemic could widen existing income inequality across societies.

\section{Figure 8: Differences in Tele-workability between Top and Bottom Earnings Deciles across Countries}

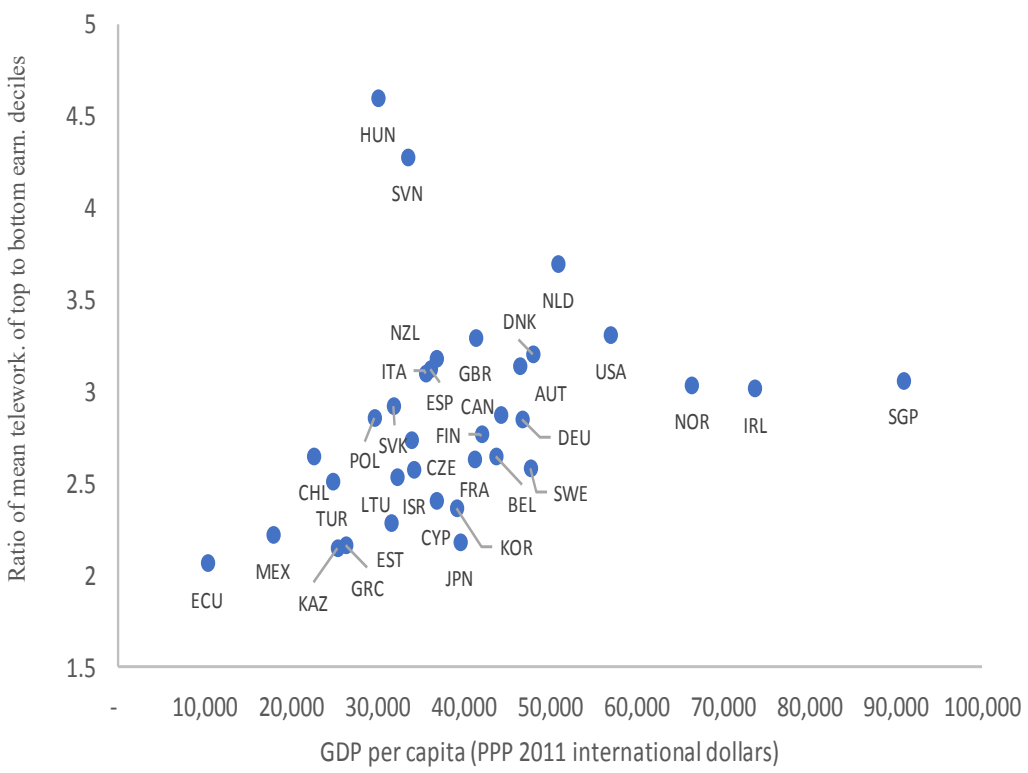

Source: PIAAC survey; Dingel and Neiman (2020); and staff calculations.

Note: Each dot corresponds to the country level ratio defined as (Mean tele-workability in top hourly

earnings decile)/ (Mean tele-workability in bottom hourly earnings decile).

\section{Estimates of Employment at Risk}

We estimate the number of workers at risk of layoff or furlough as a result of low teleworkability. Using employment reports from the US Bureau of Labor Statistics (BLS), we create sector-level measures of employment changes between February 2020 and April 2020, adjusted for the average employment change for the same period during 2017-2019. We use these sectoral job losses to develop sector-specific thresholds of the index of tele-workability, such that the number of workers who have lower tele-workability than the threshold in the US sample corresponds with the number of actual employment losses recorded for the US. This allows us to pin down the thresholds of tele-workability index associated with the highest risk of job loss.

These thresholds are subsequently applied to the full sample of countries to evaluate the number of global workers who fall below the threshold and, are therefore, face a higher risk of layoffs or furloughs. In order to ensure that our global estimates are representative of the global labor force, we use International Labor Organization (ILO) estimates of employment by country and sector in 2019 for our global projections. In addition, we adjust for the country-specific stringency of the lockdown measures, using the stringency index from the Coronavirus Government Response Tracker (Oxford University, 2020). We select the highest value of the index 
for April 2020 and normalize the index to the US value, given that the threshold is based on the BLS employment data.

Our results suggest that over 97.3 million workers, or more than 15 percent of the workforce, are at high risk of layoffs and furloughs due to lockdown measures in the 35 countries in our sample. US accounts for over 21 million of these jobs, or about 13 percent of employment, in line with the April 2020 BLS Employment Situation report. The worst hit sectors are restaurants and accommodation with close to 17.6 million workers at risk, and wholesale and retail with over 13.9 million workers at risk of layoffs and furloughs across 35 countries in our sample (Annex 4).

\section{Conclusions}

We develop a new index of the feasibility to work from home for 35 advanced and emerging economics. We show that workers differ across characteristics that are most likely to be hit by the stringent social distancing policies required to stop the spread of the pandemic. Across countries, those with a low score on the tele-workability index tend to be the more economically vulnerable: workers that are young, with fewer years of education, engaging in part-time work, and with earnings toward the bottom of the distribution. Many of these worker characteristics coalesce in the hardest-hit occupations and sectors.

Our analysis does not explicitly distinguish between "social" jobs which require face-to-face interaction for consumption, tele-workable jobs, and "essential" jobs which were not subject to government mandated lockdowns. For instance, women are both more likely to be in high workfrom-home occupations and be employed as essential workers, suggesting that the immediate impact of strict social distancing policies on their employment prospects could be less severe in some countries. However, we show that workers in jobs that require face-to-face interactions (e.g., accommodation and food services and retail) are also most at risk of layoffs and furloughs, suggesting that women could be disproportionately at risk.

There are significant differences in the scope to work remotely across countries. In emerging market economies such as Turkey, Peru, and Mexico, fewer than half the households have access to a computer at home. Further, irrespective of the type of occupation, pervasive informal working arrangements (e.g., high share of self-employed and casual work) in these countries make it more challenging to work remotely from home (Gottlieb, Grobovsek, and Poschke, 2020). Workers in such arrangements are also less likely to have access to health care and the formal insurance channels that can help them weather the crisis. Informal workers in these countries could thus face a dramatically higher risk of falling into poverty and will experience greater challenges in regaining their livelihoods during the recovery. Social protection responses in the must reach these workers and their families quickly and effectively to cushion them against the shock.

The impact of COVID-19 on employment and the distribution of job losses across sectors and countries will depend on the severity and duration of containment measures and the depth and breadth of economic contractions. Evidence from past crises suggests that job losses during severe recessions can have lasting, negative effects on future earnings and job security. The 
impact on low-income and precariously employed workers could be particularly severe, widening income inequality within countries. Changed consumer preferences following the COVID-19 outbreak, such as greater reliance on e-commerce and altered tastes for goods and services, could also have a significant future impact on employment prospects and how work is carried out. For instance, a significant share of the demand for retail, tourism, dining out and personal services that is lost during the crisis may never return. Policy responses should appropriately account for these demographic and distributional considerations both during the crisis and in its aftermath. 
Annex 1. Occupational Classifications

\section{Occupation (ISCO 2 digit)}

\begin{abstract}
Professional
\end{abstract}
Technicians \& assoc. prof.

Legislators, senior officials, \& managers

Clerks

Crafts \& trade

Service, shop, \& market

Plant/machine operators

Elementary

\section{Occupation (ISCO 4 digit)}

Science and engineering professionals

Health professionals

Teaching professionals

Business and administration professionals

Information and communications technology professionals

Legal, social and cultural professionals

Science and engineering associate professionals

Health associate professionals

Business and administration associate professionals

Legal, social, cultural and related associate professionals

Information and communications technicians

Chief executives, senior officials and legislators

Administrative and commercial managers

Production and specialized services managers

Hospitality, retail and other services managers

General and keyboard clerks

Customer services clerks

Numerical and material recording clerks

Other clerical support workers

Building and related trades workers, excluding electricians

Metal, machinery and related trades workers

Handicraft and printing workers

Electrical and electronic trades workers

Food processing, wood working, garment and other craft and

related trades workers

Personal service workers

Sales workers

Personal care workers

Protective services workers

Stationary plant and machine operators

Assemblers

Drivers and mobile plant operators

Cleaners and helpers

Agricultural, forestry and fishery laborers

Laborers in mining, construction, manufacturing and transport

Food preparation assistants

Street and related sales and service workers

Refuse workers and other elementary workers

\section{CInternational Monetary Fund. Not for Redistribution}




\section{Annex 2: Country Estimates of Tele-workability Differences by Worker Characteristics}

\begin{tabular}{|c|c|c|c|c|c|c|c|c|c|}
\hline & Male & $\begin{array}{c}\text { No } \\
\text { College } \\
\text { Degree }\end{array}$ & $\begin{array}{c}\text { Below } 30 \\
\text { years of age }\end{array}$ & $\begin{array}{c}\text { Above } 60 \\
\text { years of age }\end{array}$ & $\begin{array}{l}\text { Bottom two } \\
\text { income } \\
\text { deciles }\end{array}$ & $\begin{array}{l}\text { Top two } \\
\text { income } \\
\text { deciles }\end{array}$ & $\begin{array}{l}\text { Born } \\
\text { abroad }\end{array}$ & $\begin{array}{c}\text { Firms of less } \\
\text { than } 250 \\
\text { workers }\end{array}$ & Part-time \\
\hline All Countries & $-0.069 * * *$ & $-0.115^{* * *}$ & $-0.038^{* * *}$ & $0.009^{* \star *}$ & $-0.116^{\star * \star}$ & $0.181^{\star \star \star}$ & $-0.067^{* * \star}$ & $-0.078^{* * *}$ & $-0.057^{\star * *}$ \\
\hline Austria & $0.022^{*}$ & $0.060^{* * *}$ & -0.009 & 0.023 & -0.003 & 0.012 & -0.005 & $0.032^{\star \star}$ & $0.041^{* * *}$ \\
\hline Belgium & 0.005 & $0.094^{\star * *}$ & 0.018 & 0.060 & -0.002 & -0.012 & -0.025 & $0.031^{*}$ & $0.035^{* *}$ \\
\hline Canada & $-0.018^{\star * *}$ & 0.006 & $-0.043^{\star * *}$ & -0.004 & $-0.026^{\star \star *}$ & -0.002 & $0.066^{\star * *}$ & -0.010 & \\
\hline Chile & -0.011 & $0.050^{\star \star \star}$ & $0.033^{\star \star \star}$ & $-0.043^{\star \star}$ & $0.020^{*}$ & -0.010 & 0.017 & -0.014 & $0.032^{\star \star}$ \\
\hline Cyprus & -0.043 & 0.035 & 0.043 & -0.068 & 0.038 & -0.049 & 0.055 & 0.047 & 0.019 \\
\hline Czech Republic & -0.002 & $0.026^{*}$ & $0.034^{\star *}$ & -0.029 & 0.021 & -0.012 & 0.017 & $0.054^{\star \star \star}$ & 0.030 \\
\hline Germany & $0.025^{\star * *}$ & $0.063^{* * *}$ & $-0.017^{\star \star \star}$ & -0.010 & 0.002 & $0.036^{* * *}$ & $-0.049^{* * *}$ & $-0.015^{* * *}$ & $0.024^{\star \star *}$ \\
\hline Denmark & 0.003 & $0.035^{\star \star}$ & $-0.065^{\star * \star}$ & 0.040 & $-0.028^{*}$ & 0.012 & 0.013 & $-0.029 *$ & 0.009 \\
\hline Ecuador & $-0.054^{\star \star \star}$ & $-0.070^{* * *}$ & $0.024^{\star \star \star}$ & -0.049 & $0.025^{\star}$ & $-0.038^{* * *}$ & & -0.010 & -0.022 \\
\hline Spain & 0.000 & $-0.092^{* * *}$ & 0.011 & 0.008 & 0.006 & $0.022^{* * *}$ & $-0.036^{* * *}$ & $0.015^{\star}$ & 0.005 \\
\hline Estonia & -0.036 & 0.024 & 0.026 & -0.008 & 0.006 & $-0.057^{\star}$ & -0.002 & 0.031 & 0.048 \\
\hline Finland & -0.005 & $0.058^{\star \star \star}$ & $-0.045^{\star \star \star}$ & 0.018 & -0.010 & -0.012 & -0.008 & 0.001 & 0.003 \\
\hline France & $-0.017^{\star \star \star *}$ & $0.027^{\star \star \star}$ & $0.029^{\star \star \star \star}$ & 0.010 & $0.018^{\star \star \star \star}$ & $0.021^{\star \star \star}$ & $-0.019^{\star * \star}$ & $0.021^{\star \star \star}$ & $0.022^{\star * \star}$ \\
\hline United Kingdom & 0.001 & -0.001 & -0.006 & -0.008 & $-0.038^{\star * *}$ & $0.045^{\star \star *}$ & $0.046^{\star \star \star}$ & -0.004 & -0.003 \\
\hline Greece & -0.008 & 0.013 & 0.013 & 0.026 & $0.050^{\star * *}$ & -0.027 & -0.018 & 0.010 & -0.010 \\
\hline Hungary & $-0.038^{* * *}$ & $-0.023^{\star *}$ & $0.034^{\star *}$ & $-0.035^{\star}$ & -0.013 & $0.046^{* * *}$ & $0.080^{* *}$ & 0.001 & -0.002 \\
\hline Ireland & -0.006 & -0.010 & -0.010 & -0.053 & -0.011 & 0.000 & 0.025 & -0.027 & $-0.035^{\star}$ \\
\hline Israel & $-0.028^{\star \star}$ & -0.011 & $-0.049^{* * *}$ & 0.012 & -0.024 & 0.009 & 0.023 & $-0.030^{\star}$ & -0.013 \\
\hline Italy & $-0.028^{\star * *}$ & $-0.089^{* * *}$ & $0.015^{\star *}$ & 0.015 & $0.016^{\star \star}$ & $-0.014^{\star *}$ & $-0.058^{* * *}$ & 0.011 & $0.037^{\star \star *}$ \\
\hline Japan & $0.084^{* * *}$ & $0.038^{\star * *}$ & -0.004 & $-0.059^{* * *}$ & $0.037^{* * *}$ & $-0.036^{* * *}$ & $0.088^{* * *}$ & $-0.028^{\star * \star}$ & $-0.032^{* * *}$ \\
\hline Kazakhstan & $-0.057^{\star \star \star}$ & $0.023^{* *}$ & $0.079^{\star \star \star}$ & $-0.059^{\star \star}$ & $0.053^{* \star \star}$ & $-0.071^{\star \star \star}$ & -0.003 & $0.049^{\star \star \star}$ & 0.024 \\
\hline Korea & $0.050^{\star * \star}$ & $0.030^{* * *}$ & $0.088^{\star * \star}$ & $-0.118^{\star \star \star}$ & -0.004 & $-0.061^{\star \star \star}$ & $-0.078^{* * *}$ & -0.011 & $-0.050^{\star \star *}$ \\
\hline Lithuania & $-0.051^{* \star}$ & 0.024 & $0.048^{* *}$ & -0.010 & 0.024 & 0.007 & 0.015 & 0.038 & 0.050 \\
\hline Mexico & $-0.027^{\star \star \star}$ & $-0.079^{* * *}$ & $0.033^{* * *}$ & $-0.049^{\star \star \star}$ & $0.060^{* * *}$ & $-0.031^{* * *}$ & $0.203^{* * *}$ & $0.043^{* * *}$ & $0.033^{\star * *}$ \\
\hline Netherlands & $0.022^{\star \star \star}$ & $-0.057^{* * *}$ & $-0.045^{\star \star \star}$ & 0.000 & $-0.058^{* * *}$ & 0.003 & 0.012 & -0.003 & $0.049^{\star * *}$ \\
\hline Norway & $0.024^{*}$ & -0.016 & $-0.071^{\star \star \star}$ & 0.024 & $-0.032^{*}$ & -0.012 & 0.008 & -0.006 & -0.023 \\
\hline New Zealand & -0.016 & -0.023 & $-0.037^{\star \star}$ & 0.012 & -0.031 & 0.028 & $0.083^{\star * *}$ & $-0.041^{\star}$ & 0.006 \\
\hline Peru & 0.007 & $0.040^{\star * *}$ & $0.057^{* * *}$ & 0.001 & & & $0.160^{\star \star \star}$ & -0.002 & $0.033^{\star \star \star}$ \\
\hline Poland & $-0.053^{\star * \star}$ & 0.011 & $0.038^{\star * \star}$ & -0.017 & 0.003 & 0.004 & $0.145^{\star \star}$ & $0.062^{\star \star \star}$ & $0.043^{\star \star \star}$ \\
\hline Singapore & 0.004 & $-0.033^{\star *}$ & $0.049^{* * *}$ & $-0.084^{\star \star \star}$ & $-0.065^{\star \star *}$ & -0.011 & $0.096^{* * *}$ & 0.003 & $-0.074^{\star * *}$ \\
\hline Slovak Republic & $-0.027^{\star}$ & $-0.065^{\star * \star}$ & $0.052^{* \star *}$ & -0.003 & -0.004 & -0.018 & 0.065 & $0.070^{\star \star \star}$ & 0.011 \\
\hline Slovenia & -0.030 & $0.074^{\star * *}$ & 0.007 & 0.060 & -0.034 & 0.037 & $-0.071^{\star}$ & $0.102^{* * *}$ & 0.032 \\
\hline Sweden & 0.001 & $0.044^{* * *}$ & $-0.045^{\star \star *}$ & 0.017 & 0.003 & -0.015 & 0.010 & 0.005 & -0.008 \\
\hline Turkey & $-0.017^{\star \star \star}$ & $-0.035^{* * *}$ & $0.038^{* * *}$ & -0.001 & $0.055^{* * *}$ & $-0.046^{* * *}$ & 0.000 & $0.051^{\star \star *}$ & 0.016 \\
\hline United States & $-0.025^{\star \star \star}$ & 0.002 & $-0.048^{\star \star \star}$ & $0.071^{\star \star \star}$ & $-0.044^{\star \star \star}$ & $0.025^{\star \star \star}$ & -0.004 & $-0.014^{\star \star \star}$ & $-0.029 * * *$ \\
\hline
\end{tabular}

Note: Table contains estimates of country differences from regressions where tele-workability index is regressed on one of the worker characteristics, with an interaction term for the country capturing country differences from the full sample mean. Each worker characteristic variable takes on a value of 1 , indicating whether an individual belongs to a given group, or 0 . Blank cells are not estimated for a given country due to lack of variable availability in the data. Full sample of 35 countries contains 151,177 observations. 
Annex 3. Gender Differences Across Sectors and Occupations

$\begin{gathered}\text { Distribution of Male and Female Workers } \\ \text { across Occupations } \\ \text { Male Female }\end{gathered}$
Elementary
Plant/Machinery
Crafts/trade
Service/Shop/Market
Technicians
Clerks
Legislators/Managers
Professionals
Source: PIAAC survey and staff calculations.
Note: Occupations are ordered by level of tele-workability
from lowest to highest. Darker colors indicate higher
concentration of workers in a given occupation.

\section{Distribution of Male and Female Workers across Sectors}

Accommodation/Food

Construction

Transportation

Admin./Support

Wholesale/Retail

Manufacturing

Health/Social Serv.

Public Admin./Defence

Education

Professional

Finance/Insurance

Information/Comm

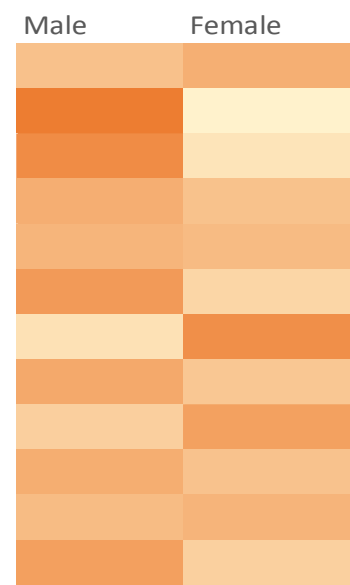

Source: PIAAC survey and staff calculations.

Note: Sectors are ordered by level of tele-workability from lowest to highest. Darker colors indicate higher

concentration of workers in a given sector. 
Annex 4: Employment at Risk Estimates

\section{Employment at Risk: Estimates by Sector}

\begin{tabular}{|c|c|c|}
\hline & $\begin{array}{l}\text { Employment at risk } \\
\text { (in thousands) }\end{array}$ & $\begin{array}{c}\text { Share of } \\
\text { employment at risk }\end{array}$ \\
\hline Accommodation/Food Services & 17,666 & 0.47 \\
\hline Wholesale/Retail Trade & 13,902 & 0.15 \\
\hline Manufacturing & 12,258 & 0.14 \\
\hline Other Services & 11,209 & 0.31 \\
\hline Health/Social Services & 9,784 & 0.14 \\
\hline Transportation & 7,642 & 0.15 \\
\hline Education & 7,340 & 0.15 \\
\hline Construction & 6,693 & 0.15 \\
\hline Administrative/Support Activities & 5,587 & 0.09 \\
\hline Public Administration/Defense & 2,674 & 0.08 \\
\hline Finance/Insurance & 1,414 & 0.07 \\
\hline Agriculture & 936 & 0.03 \\
\hline Utilities & 118 & 0.02 \\
\hline Mining & 108 & 0.04 \\
\hline
\end{tabular}

Source: PIAAC Survey; BLS; ILO; and staff calculations.

Note: Estimates are based on the sample of 35 countries available in the PIAAC survey. 


\section{References}

Alonso, C., Brussevich, M., Dabla-Norris, E., Kinoshita, Y. and Kochhar, 2019, "Reducing and Redistributing Unpaid Work: Stronger Policies to Support Gender Equality", IMF Working Paper No.19/225.

Arntz, M., Gregory, T., and U. Zierahn, 2017, "Revisiting the Risk of Automation", Economics Letters, 159, 157-160.

Boeri, T., Caiumi, A. and Paccagnella, M., 2020, "Mitigating the Work-Security Trade-off while Rebooting the Economy," CEPR Covid Economics 2.

Brussevich, M., E. Dabla-Norris, and S. Khalid, 2019, "Is Technology Widening the Gender Gap? Automation and the Future of Female Employment," IMF Working Paper No. 19/91.

BLS - Bureau of Labor Statistics (2020), "The Employment Situation - April 2020."

Chen, T., Hallaert, J. J., Pitt, A., Qu, H., Queyranne, M., Rhee, A., Shabunina, A., Vandenbussche, J., Yackovlev, I. (2018) "Inequality and Poverty Across Generations in the European Union." IMF Staff Discussion Note 18/01.

Dabla-Norris, E., C. Pizinelli, and J. Rapppaport, 2019, "Job Polarization and Declining of the Young: Evidence from the UK," IMF Working Paper No.19/216.

Dingel, J. and B. Neiman, 2020, "How Many Jobs Can Be Done at Home?" NBER Working Paper No. 26948.

Fadinger, H. and J. Schymik, 2020, "The Costs and Benefits of Home Office During the Covid-19 Pandemic: Evidence from Infections and an Input-Output model for Germany," CEPR Covd Economics 9.

Gottlieb, C., J. Grobovsek, and M. Poschke, 2020, "Working from Home across Countries," CEPR Covid Economics 8.

Hensvik, L., Le Barbanchon, T. and Rathelot, R., 2020, "Which Jobs are Done from Home? Evidence from the American Time Use survey," IZA Discussion Paper 13138.

ILO - International Labor Organization (2020), ILO Monitor 2nd edition: COVID-19 and the World of Work.

Mongey, S., Pilossoph, L., and A. Wienberg, 2020, "Which Workers Bear the Burden of Social Distancing Policies?," CEPR Covid Economics 12.

OECD, 2020, "COVID-19: SME Policy Responses," note prepared by OECD Centre for Entrepreneurship, SMEs, Regions and Cities. 
Office of National Statistics, 2020, "Coronavirus and Homeworking in the UK Labour Market: 2019."

Oxford University, 2020, "Coronavirus Government Response Tracker," Blavatnik School of Government.

Saltiel, F., 2020, "Home Working in Developing Countries," CEPR Covid Economics 6. 